\title{
Expression of Neuronal Connexin36 in AII Amacrine Cells of the Mammalian Retina
}

\author{
Andreas Feigenspan, ${ }^{1}$ Barbara Teubner, ${ }^{2}$ Klaus Willecke, ${ }^{2}$ and Reto Weiler ${ }^{1}$ \\ ${ }^{1}$ Department of Biology, Carl von Ossietzky Universität, 26111 Oldenburg, Germany, and 2Institute for Molecular Genetics, \\ Universität Bonn, 53117 Bonn, Germany
}

We have studied the expression pattern of neuronal connexin36 (Cx36) in the mouse and rat retina. In vertical sections of both retinas, a polyclonal antibody directed against Cx36 produced punctate labeling in the inner plexiform layer (IPL). Intense immunoreactivity was localized to the entire OFF sublamina of the IPL, and much weaker staining could be observed in the ON sublamina. Double-labeling experiments in the rat retina with antibodies directed against parvalbumin indicate that $\mathrm{Cx36}$ is expressed on dendrites of All amacrine cells. Cx36-like immunoreactivity in sublamina a of the IPL did not overlap with lobular appendages or cell bodies of All amacrine cells. In a mouse retinal slice preparation, All amacrine and ON cone bipolar cells were intracellularly injected with Neurobiotin and counterstained with antibody against Cx36. Punctate labeling appeared to be in register with dendritic arborization of All amacrines and cone bipolar cells in the ON sublamina of the IPL. Whereas All amacrine cells isolated from the rat retina clearly displayed $\mathrm{Cx} 36$-like immunoreactivity, isolated ON cone bipolar cells were negative for Cx36. Axon terminals of rod bipolar cells were decorated with $\mathrm{Cx36}$-positive contacts but did not express Cx36 themselves.

These results indicate that $\mathrm{C} \times 36$ is expressed by All amacrine cells in homologous and heterologous gap junctions made with All amacrines and cone bipolar cells, respectively. The heterologous gap junctions appear to be heterotypic, because ON cone bipolar cells do not express Cx36.

Key words: gap junction; connexin36; retina; All amacrine cell; cone bipolar cell; scotopic pathway
In the vertebrate retina, gap junctions have been demonstrated in all major cell types and also in supporting glial cells (Vaney, 1994) (for review, see Cook and Becker, 1995). Many diverse types of neurons show stereotyped patterns of tracer coupling when injected with small biotinylated molecules (Vaney, 1991). Electrotonic coupling mediated by gap junctions has been proposed to be responsible for synchronization of signals in various brain regions (Draguhn et al., 1999; Galarreta and Hestrin, 1999; Tamas et al., 2000) and also in the retina for neuronal adaptation (for review, see Sterling, 1995; Weiler, 1996; Weiler et al., 2000b).

Gap junctions are arrays of intercellular channels in specialized membrane areas that permit passage of ions, second messengers, and small metabolites up to $1 \mathrm{kDa}$ in size (Bruzzone et al., 1996; Goodenough et al., 1996). The channels are formed by docking of two hemichannels termed connexons, which are hexameric structures of subunit proteins called connexins. So far, 15 different connexins have been described in the rodent genome, with many homologous proteins identified in other species (Beyer et al., 1990; Willecke et al., 1991; Haefliger et al., 1992; White et al., 1992; Bruzzone et al., 1996; Dahl et al., 1996).

The first neuronal type shown to make gap junctions in the inner retina was the AII amacrine cell (Kolb and Famiglietti, 1974; Famiglietti and Kolb, 1975). This cell represents the major output of rod bipolars and establishes homologous gap junctions

\footnotetext{
Received June 12, 2000; revised Oct. 4, 2000; accepted Oct. 12, 2000.

This work was supported by the Deutsche Forschungsgemeinschaft (Sonderforschungsbereich 517). We thank Dr. David Vaney for critical reading of an earlier draft of this manuscript, Dr. Konrad Schultz, Dr. Mark Pottek, and Timm Schubert for technical assistance, and Dr. Steve C. Massey for sharing unpublished material,

Correspondence should be addressed to Dr. Andreas Feigenspan, Department of Biology, Carl von Ossietzky Universität, 26111 Oldenburg, Germany. E-mail: andreas.feigenspan@uni-oldenburg.de.

Copyright (C) 2001 Society for Neuroscience $\quad 0270-6474 / 01 / 210230-10 \$ 15.00 / 0$
}

with neighboring AII amacrines in the most vitreal region of the inner plexiform layer (IPL), as well as heterologous junctions with axon terminals of cone bipolar cells in sublamina $b$ of the IPL (Kolb and Famiglietti, 1974; Strettoi et al., 1992). Rod signals generated under scotopic light condition are funneled into the cone system through these heterologous amacrine bipolar junctions. It has been shown recently that both junctional pathways display differential properties in terms of relative permeability and modulation by cAMP and cGMP agonists, respectively (Mills and Massey, 1995). However, the molecular identity of the connexins involved in forming both types of gap junctions has not yet been resolved.

In the CNS, a number of different connexins are expressed, which could be localized to astrocytes and oligodendrocytes (Dermietzel and Spray, 1998), as well as pigment epithelial cells in the vertebrate retina (Janssen-Bienhold et al., 1998). Recently, a novel connexin ( $\mathrm{Cx} 35)$ has been cloned, which is expressed at high levels in the skate retina (O'Brien et al., 1996) and the homologous $\mathrm{Cx} 34.7$ expressed in both retina and brain of the perch (O'Brien et al., 1998). The mammalian homolog Cx36 is expressed preferentially in the retina and various neuronal tissues, most notably the olfactory bulb, developing cortex, and CA3/CA4 regions of the hippocampus (Condorelli et al., 1998; Söhl et al., 1998; Srinivas et al., 1999). The aim of this study was to investigate the cellular localization of Cx36 in the mouse and rat retina and to correlate the expression pattern with gap junctions made by AII amacrine cells.

Parts of this work have been published previously in abstract form (Weiler et al. 2000a).

\section{MATERIALS AND METHODS}

Tissue preparation. Adult albino rats and adult albino mice were deeply anesthetized and killed by cervical dislocation. The eyecup was removed 
and fixed in $4 \%$ paraformaldehyde (PA) for $40 \mathrm{~min}$. After rinsing in 0.1 $\mathrm{M}$ phosphate buffer, $\mathrm{pH} 7.4$ (PB), the eyecup was immersed in $30 \%$ sucrose in $\mathrm{PB}$ overnight before sectioning. Frozen vertical and horizontal sections of $15 \mu \mathrm{m}$ thickness were taken on a cryostat, collected on gelatinized slides, air dried, and stored at $-20^{\circ} \mathrm{C}$.

In general, the polyclonal antibody directed against $\mathrm{Cx} 36$ caused nonspecific cytoplasmic staining of rod bipolar cell axons in paraformaldehydefixed tissue. This nonspecific staining disappeared when using ethanol. For double-labeling experiments, however, PA could not be avoided, because the other primary antibodies definitely required PA fixation. We therefore decided to consistently apply PA fixation in all experiments.

For tissue slices, which were used for injection of Lucifer yellow (LY) and Neurobiotin (NB), the retina was removed from the sclera and cut into quarters. One of the quarters was transferred to the stage of a tissue chopper (McIlwain) and cut with a razor blade into slices of 100-200 $\mu \mathrm{m}$ thickness. The slices were immediately fixed in 4\% PA for 15-20 min and rinsed in $\mathrm{PB}$ several times before further processing.

Immunocytochemistry and antibodies. A 15 amino acid peptide (LNQTETTSKETEPDX) corresponding to part of the cytoplasmic loop of mouse connexin36 (Cx36) was synthesized, coupled to keyhole limpet hemocyanin, and injected into rabbits at Eurogentec (Seraing, Belgium). Serum was affinity purified with the same peptide using a HiTrap affinity column (Amersham Pharmacia Biotech, Uppsala, Sweden). After elution with 3 m potassium thiocyanate in PBS and dialysis against PBS containing $0.01 \%$ sodium azide, the antibodies were concentrated by ultrafiltration through Centricon micro tubes 30 (Amicon, Beverly, MA) and finally stored in PBS with $0.5 \%$ bovine serum albumin and $0.02 \%$ sodium azide. The antibody was used at a working dilution of 1:500 to 1:1000.

A monoclonal antibody against parvalbumin was purchased from Sigma [(St. Louis, MO) clone PARV-19] and used at a dilution of 1:1000. A monoclonal antibody against the $\alpha$ isoform of protein kinase C (PKC) was purchased from Amersham Pharmacia Biotech (clone MC 5). A polyclonal antibody directed against recoverin was kindly provided by Dr. H. Wässle (Max-Planck-Institute for Brain Research, Frankfurt, Germany).

For immunocytochemistry, all sections were preincubated in a solution containing $10 \%$ normal goat serum (NGS) and $0.3 \%$ Triton X-100 in PB for $1 \mathrm{hr}$. The primary antibodies were diluted in a solution containing $3 \%$ NGS and $0.3 \%$ Triton $\mathrm{X}-100$ in $\mathrm{PB}$, and the sections were incubated in this solution for 12-14 hr. After several washes in PB, the sections were incubated in the secondary antibody diluted in $0.3 \%$ Triton X-100 in PB for $2 \mathrm{hr}$.

To visualize immunoreactivity with fluorescence, the following secondary antibodies were used: goat anti-mouse Alexa 488 (diluted 1:250; Molecular Probes, Eugene, OR), goat anti-rabbit Alexa 568 (diluted 1:200; Molecular Probes), donkey anti-mouse Cy3 (diluted 1:300; Dianova, Hamburg, Germany), and FITC-streptavidin conjugate (diluted 1:200; Amersham Pharmacia Biotech). For double-immunofluorescence with a combination of monoclonal and polyclonal antibodies, sections were incubated in a mixture of two of the primary antibodies and rinsed in $\mathrm{PB}$, followed by incubation in a mixture of two secondary antibodies. To prevent bleaching, sections were coverslipped in VectaShield (Vector Laboratories, Burlingame, CA). For Cx36-recoverin double-labeling, a protocol was designed that allowed double-labeling with two rabbit polyclonal antibodies. Rat retinal sections were first labeled for recoverin as described above, using goat anti-rabbit Alexa 568 as secondary antibody. The Cx36 antibody was prelabeled by incubation for $2 \mathrm{hr}$ at room temperature with anti-rabbit biotin at a 10 -fold molar excess of primary antibody. Vertical sections were then incubated overnight with the prelabeled Cx36 antibody. The retina was washed in PB and incubated for 2 $\mathrm{hr}$ at room temperature in streptavidin-coupled FITC $(1: 150)$. Using this protocol, no cross-labeling of the primary antibodies was observed.

Staining of Neurobiotin-filled cells. AII amacrine and ON cone bipolar cells were injected in mouse retinal slices with $0.5 \%$ LY (Sigma) and 3\% NB (Vector Laboratories) in $0.1 \mathrm{~m}$ Tris buffer, $\mathrm{pH} 7.6$, using sharp filling electrodes. Using infrared videomicroscopy, middle-sized, pear-shaped cell bodies located at the border between inner nuclear layer (INL) and inner plexiform layer were chosen. For staining of cone bipolar cells, smaller cell bodies in the upper third of the INL were injected. After penetrating the cell membrane with the filling electrode, a negatively charged current $(-1 \mathrm{nA})$ was applied for at least 1 min to inject LY into the cell. When the morphology of the cell could be evaluated, the direction of current was reversed $(5 \mathrm{nA}, 15-20 \mathrm{~min})$ to inject positively charged NB molecules.

After the injection of LY and NB, the slices were fixed once more in
4\% PA for $10-15$ min and rinsed several times in PB. Then, the slices were incubated in rabbit anti-Cx36 antibody overnight, followed by a mixture of goat anti-rabbit Alexa 568 and FITC-streptavidin conjugate for $2 \mathrm{hr}$.

Images were taken on a confocal laser scanning microscope (Leica, Nussloch, Germany), using the 488 and $568 \mathrm{~nm}$ lines of a krypton-argon laser. For double-labeling experiments, optical sections of $200-250 \mathrm{~nm}$ thickness were cut individually for each channel. The images for the red and green channel thus obtained were opened separately in Adobe Photoshop (Adobe Systems, San Jose, CA) and superimposed as individual layers in a single picture. Using the option "Difference" in the layer menu, layers with red and green color components could be merged with overlapping regions appearing yellow.

To convince ourselves that the colocalization of $\mathrm{Cx} 36$ on the dendrites of filled AII amacrines is not caused by random distribution, we counted the number of Cx36-positive puncta in a series of $200 \mathrm{~nm}$ sections obtained from three different cells. Then, the image of the AII amacrine cell was flipped horizontally, and the resulting mirror image was again projected onto the pattern of Cx36 labeling. Colocalized puncta per section were then counted in this configuration as above.

Dissociation of the retina. Eyes were enucleated from 1- to 12-monthold albino rat and mice, and after removal of cornea, lens, and vitreous body, they were transferred to a solution containing $20 \mathrm{U} / \mathrm{ml}$ papain (Worthington, Freehold, NJ) and 200 U/ml Dnase I (Sigma) in Earle's Balanced Salt Solution (EBSS) (Sigma). At the end of the digestion $\left(40-45 \mathrm{~min}, 36^{\circ} \mathrm{C}\right)$, the eyecups were washed in a solution to stop papain activity $\left(5 \mathrm{~min}, 36^{\circ} \mathrm{C}\right)$. This solution contained $1 \mathrm{mg} / \mathrm{ml}$ ovomucoid (Worthington), $1 \mathrm{mg} / \mathrm{ml}$ bovine serum albumin (Sigma), and $100 \mathrm{U} / \mathrm{ml}$ Dnase I in EBSS. Then, the retinal pieces were carefully detached from the eyecup and centrifuged at $1000 \mathrm{rpm}$ for $5 \mathrm{~min}$. The pellet was resuspended in Minimum Essential Medium and triturated using firepolished Pasteur pipettes of varying bores. Aliquots of the cell suspension were deposited on round glass coverslips that had been coated with concanavalin A $(1 \mathrm{mg} / \mathrm{ml}$ in PBS) for $1-2 \mathrm{hr}$. The cells were allowed to settle on the glass for at least $30 \mathrm{~min}$ at $36^{\circ} \mathrm{C}$ in an atmosphere of $5 \% \mathrm{CO}_{2}$ and $95 \%$ air. The cells were then washed in PBS and fixed in $4 \%$ paraformaldehyde for $20 \mathrm{~min}$.

\section{RESULTS}

\section{Immunocytochemical labeling with Cx36 polyclonal antibody}

We used a polyclonal antibody directed against a 15 amino acid peptide (LNQTETTSKETEPDC) corresponding to part of the cytoplasmic loop of mouse connexin Cx36 to investigate the expression pattern of $\mathrm{Cx} 36$ in the adult rat and mouse retina.

The specificity of the antibody was tested by Western blot analysis of untransfected HeLa cells and cells transfected with Cx36. To rule out possible cross-reactivity with other connexins, HeLa cells were transfected with Cx26, 30, 31, 31.1, 32, 33, 37, 40, 43, 45, 46, 50, and 57. The antibody against Cx36 did not detect any of these connexins. A complete characterization of the polyclonal antibody against $\mathrm{Cx} 36$ has been published previously (Teubner et al., 2000). In addition, the antibody did not produce specific labeling in Cx36-deficient mice (M. Güldenagel, personal communication).

In vertical sections of both species, the antibody produced strong labeling that was characterized by a distinct punctate appearance in the IPL (Fig. 1). In the rat retina, Cx36 labeling was found to be distributed with evidence of stratification in two more intensely labeled bands (Fig. $1 B$ ). A very brightly stained band with discrete punctate appearance was located in the inner half of the IPL, corresponding to the ON sublamina. Cx36immunoreactive puncta were expressed throughout the ON sublamina, down to the ganglion cell layer (GCL). A second less strongly labeled band was located in the outer third of the IPL, corresponding to the OFF sublamina. This band was characterized by a less dense distribution of Cx36-positive label when compared with the staining pattern in the ON sublamina. 


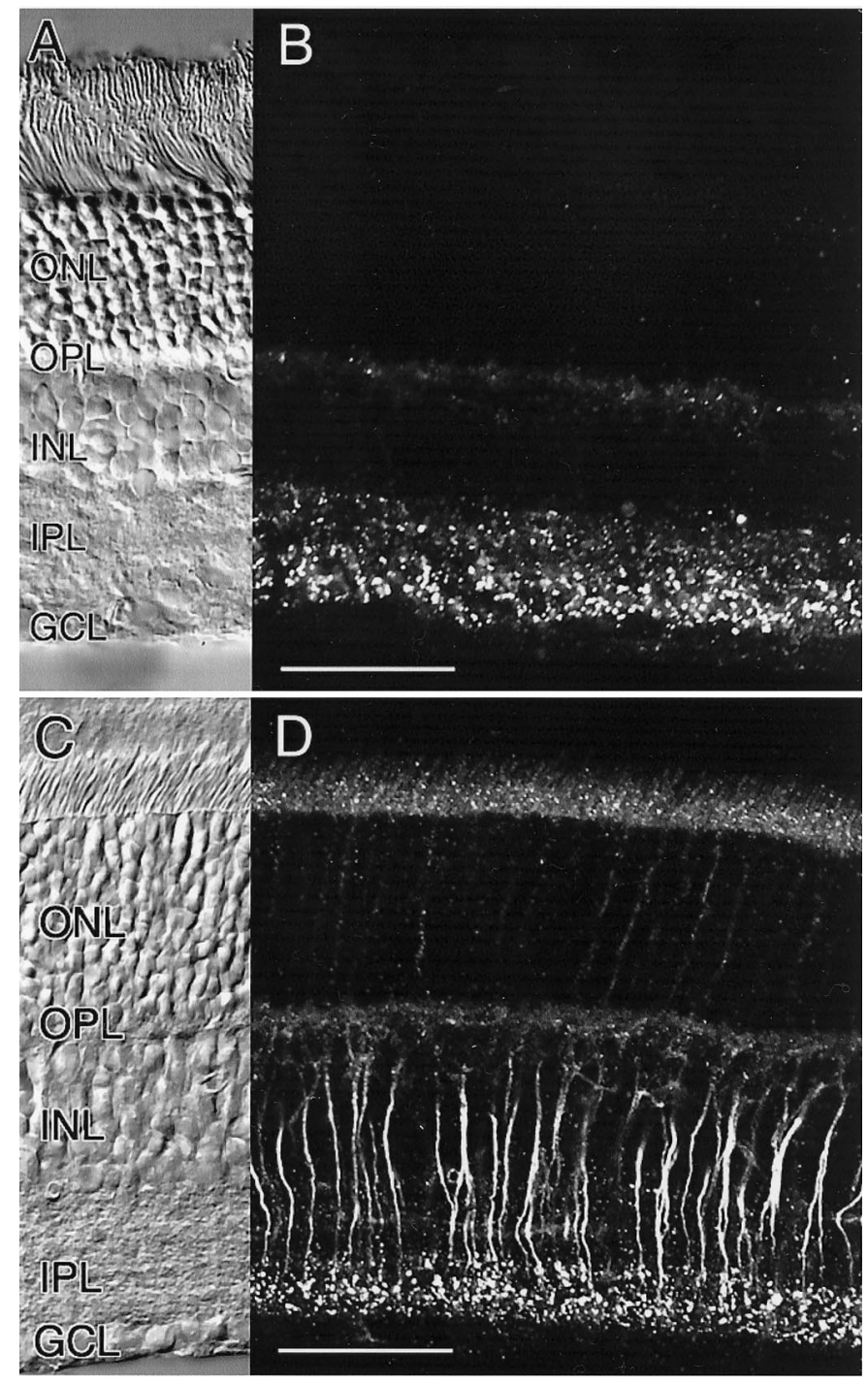

Figure 1. Immunocytochemical localization of $\mathrm{Cx} 36$ in the retina of rat and mouse. $A, B$, Pattern of $\mathrm{Cx} 36$ immunoreactivity in vertical sections of the rat retina. The corresponding Nomarski image is shown in $A$. $C, D$, Pattern of Cx36 immunoreactivity in vertical sections of the mouse retina. The cytoplasmic staining of rod bipolar cell axons is attributable to paraformaldehyde fixation (see Materials and Methods). The corresponding Nomarski image is shown in $C$. Scale bars: $A-D, 50 \mu \mathrm{m}$.

In the mouse retina, bright punctate immunolabeling was evident in the inner half of the IPL, corresponding to the ON sublamina (Fig. 1C). Staining within the OFF sublamina appeared less pronounced when compared with the rat retina. In addition, intense homogeneous labeling could be localized to the axonal cytoplasm of rod bipolar cells. The intensity of staining of rod bipolar cell bodies, however, was just above background. The cytoplasmic staining of rod bipolar cells is an artifact of fixation, because it disappears when using ethanol instead of paraformaldehyde (see Materials and Methods). The punctate labeling in the IPL, however, is not affected by either fixation protocol. The weak immunoreactivity in the outer nuclear layer (ONL) and in the inner segments of photoreceptors appeared to be nonspecific. In double-labeling experiments, we never observed colocalization of $\mathrm{Cx} 36$ with either vimentin or glial fibrillary acidic protein, thus excluding the possibility of expression of Cx36 in retinal Müller cells.
The staining in the outer plexiform layer (OPL) appeared to be nonspecific with the exception of very sparsely distributed puncta, which occurred more frequently in the rat retina. In this study, we will focus on Cx36 immunoreactivity in the IPL.

\section{Expression of Cx36 on All amacrine cell dendrites}

In the mammalian retina, AII amacrine cells and ON cone bipolar cells are heterologously coupled via gap junctions in the ON sublamina of the IPL (Famiglietti and Kolb, 1975; Strettoi et al., 1992; Chun et al., 1993). In addition, gap junctions involved in homologous coupling between pairs of AII amacrine cells have been demonstrated on their dendrites in close vicinity to the ganglion cell layer (Strettoi et al., 1992). Therefore, the discrete punctate staining in the ON sublamina of the IPL suggests the expression of Cx36 in gap junctions between AII amacrine and ON cone bipolar cells. Likewise, the presence of $\mathrm{Cx} 36$ in the vitreal densities of AII amacrine cells could indicate its expression in homotypic gap junctions between pairs of AII amacrine cells.

To test the first hypothesis, AII amacrine cells in the rat retina were double-labeled with a monoclonal antibody directed against the calcium-binding protein parvalbumin and a polyclonal antibody against $\mathrm{Cx} 36$. Parvalbumin has been shown to be a selective marker for AII amacrine cells in the rat retina (Wässle et al., 1993). Using confocal microscopy, the preparation was cut into optical sections of $200 \mathrm{~nm}$ thickness on average to avoid the false impression of colocalization attributable to the overlap of staining originating in different focal planes. As shown in Figure $2 A$, a row of parvalbumin-positive cell bodies is located on the border of inner nuclear and inner plexiform layer. The cells are bistratified with lobular appendages in the OFF sublamina of the IPL and a narrow-field dendritic tree in the ON sublamina, displaying the typical morphology of AII amacrine cells (Fig. $3 A$ ). Doublelabeling with $\mathrm{Cx} 36$ clearly indicates localization of $\mathrm{Cx} 36$ on the dendrites of AII amacrine cells (Fig. 2A,B). The colocalization is distributed evenly throughout the entire ON sublamina down to the border of IPL and ganglion cell layer, with no indication of patterning along the AII amacrine cell dendrites.

Colocalization appears to be mostly restricted to the ON sublamina of the IPL, whereas cell bodies and lobular appendages in the OFF sublamina do not display significant overlap of both Cx36 and parvalbumin (Fig. 2B). To confirm the results obtained with vertical sections, we double-stained sections of the rat retina that had been cut horizontally at the level of the ON sublamina. As shown in Figure $2 C$, there is a very close correspondence between the arrangement of $\mathrm{Cx} 36$-immunoreactive puncta and parvalbumin- positive dendritic structures, with almost all Cx36positive puncta associated with dendrites of AII amacrine cells. In agreement with result obtained from vertical sections, only minor colocalization was observed in horizontal sections cut at the level of the OFF sublamina (data not shown).

Unfortunately, parvalbumin is not an appropriate immunocytochemical marker for AII amacrine cells in the mouse retina. Therefore, we used a vertical slice preparation of the mouse retina to inject AII amacrine cells intracellularly using sharp microelectrodes. Because AII amacrine cells are the most numerous amacrine cell type in the rodent retina (Strettoi and Masland, 1996; MacNeil et al., 1999) and their cell bodies protrude into the IPL (Perry and Walker, 1980; Voigt and Wässle, 1987), they can be effectively identified using infrared videomicroscopy, and with some experience, selected with rather high success rate for intracellular injection. Every cell was injected iontophoretically with 

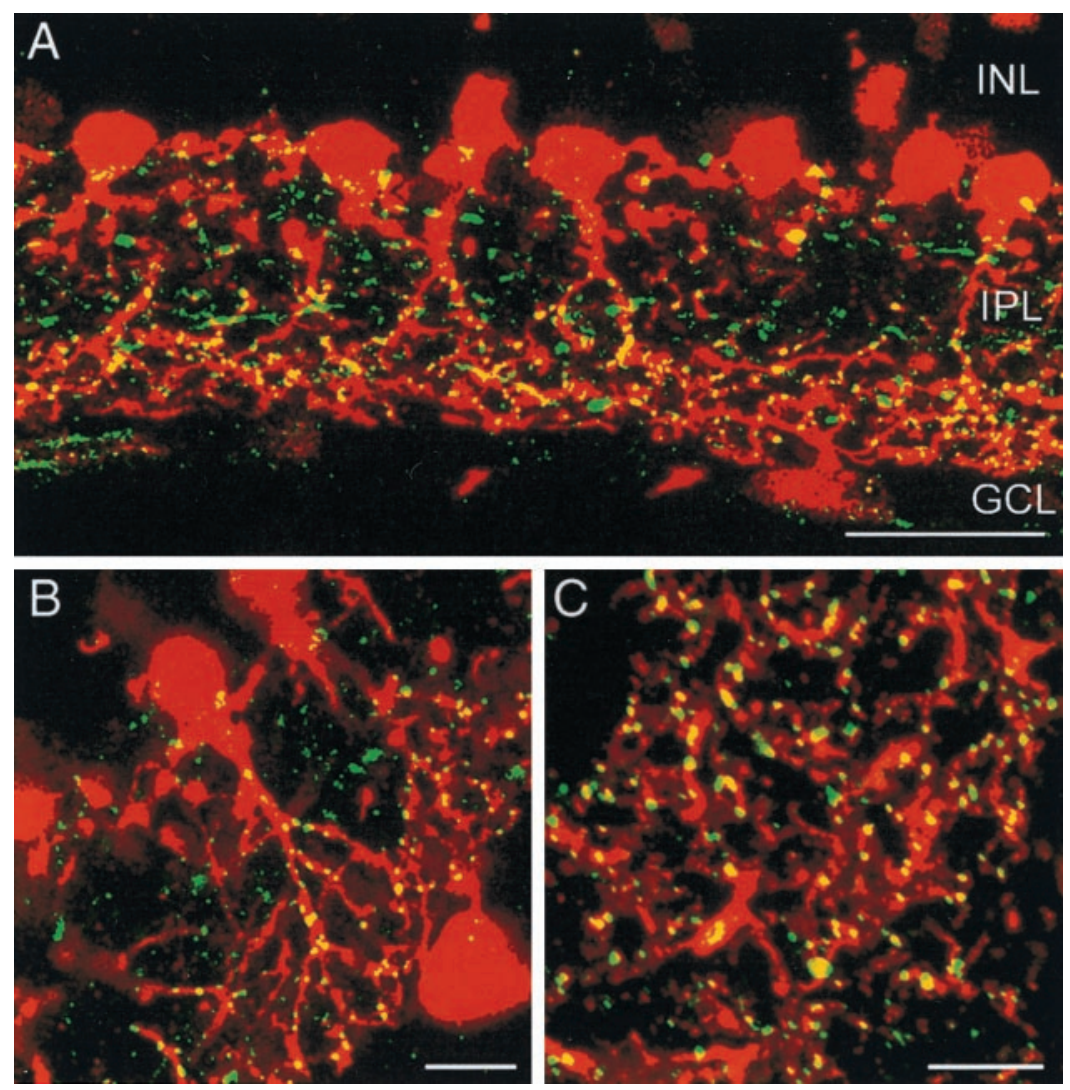

Figure 2. Expression of $\mathrm{Cx} 36$ in parvalbumin-immunoreactive cells in the rat retina. $A$, Double-labeling of a rat retina vertical section with antibodies against parvalbumin (red) and Cx36 (green). Only the vitreal half of the retina is shown. Arrows indicate lobular appendages of AII amacrine cells. $B$, Enlarged view of a single parvalbumin-positive AII amacrine cell from a different vertical section. All Cx36immunoreactive puncta in sublamina $b$ of the IPL are in register with AII amacrine cell dendrites. $C$, Horizontal section of the rat retina cut at the S3-S4 level of the IPL and double-labeled with parvalbumin (red) and Cx36 ( green). Scale bars: $A, 50 \mu \mathrm{m} ; B, C, 10 \mu \mathrm{m}$.

low concentrations of LY $(0.5 \%)$ to make sure it was an AII amacrine cell. Only those cells were chosen that displayed the typical morphology of AII amacrine cells with apparently intact dendritic trees. As soon as the morphology could be evaluated (usually $<1 \mathrm{~min}$ ), the epifluorescence illumination was shut down to minimize damage to intracellular epitopes, most likely caused by the generation of free radicals. The cells were then filled with Neurobiotin (3\%) for up to $20 \mathrm{~min}$ to ensure complete staining of the cells, post-fixed, and subsequently processed for $\mathrm{Cx} 36 \mathrm{immu}-$ noreactivity. Using this protocol, the presence of LY in the cells did not interfere with subsequent immunocytochemical labeling.

A total of 10 AII amacrine cells were filled intracellularly and immunocytochemically processed. Figure $3 A$ shows a typical AII amacrine cell in a mouse retinal slice preparation injected with Neurobiotin and visualized with streptavidin-conjugated fluorescein. Its soma is located at the border of INL and IPL, and a stout single process leaves the cell body. In the outer third of the IPL, lobular appendages are found (Fig. $3 A$, arrows), whereas in the inner third a densely branched, narrow dendritic tree is stained (Fig. 3A, arrowheads). With slightly fixed tissue, it was usually no problem to remove the filling electrode, so the overall morphology of the cell appeared well preserved.

Because the diameter of the dendritic tree of this particular cell extends over $>30 \mu \mathrm{m}$ perpendicular to the focal plane, the picture represents a projection of a stack of individual confocal scans into a single plane. In Figure $3 B$, the immunostaining against $\mathrm{Cx} 36$ corresponding to an "optical section" of $0.2 \mu \mathrm{m}$ is superimposed on the AII amacrine cell. Cx36-positive puncta in the ON sublamina of the IPL are in register with dendrites of the rod amacrine cell. Occasionally, double-labeling of dendritic tips can be observed, with $\mathrm{Cx} 36$ immunoreactivity only partially overlapping the AII amacrine cell staining. In contrast, there is no apparent colocalization of $\mathrm{Cx} 36$ on the cell body or on lobular appendages in the OFF sublamina. Figure $3 C$ shows the superposition of two optical sections taken at the same focal depth: one of the AII amacrine cell shown in Figure $3, A$ and $B$, and the other of the corresponding Cx36 immunostaining. With a thickness of $0.2 \mu \mathrm{m}$, only part of the dendritic field of the AII amacrine cell is visible; the cell body and lobular appendages are entirely out of focus. Cx36-positive puncta on amacrine cell dendrites in the ON sublamina can be clearly identified.

The colocalization of $\mathrm{Cx} 36$ on the dendrites of filled AII amacrine cells is not caused by random distribution. On average, $22.6 \pm 3.0 \mathrm{Cx} 36$-positive puncta were found in every confocal section $(n=13)$. When the image of the AII amacrine cell was flipped horizontally and the resulting mirror image was again projected onto the pattern of Cx36 labeling, we observed $6.5 \pm$ 0.6 colocalized puncta per section $(n=13)$. The difference observed is highly significant ( $p<0.01 ; t$ test), further indicating the presence of $\mathrm{Cx} 36$ on AII amacrine cell dendrites.

To provide additional proof that $\mathrm{Cx} 36$ is expressed by AII amacrine cells, we localized Cx36-positive labeling on processes of isolated cells. Rat retinal neurons were enzymatically and mechanically dissociated and double-labeled with a monoclonal antibody to parvalbumin to identify AII amacrine cells and with a polyclonal antibody directed against Cx36. During the dissociation procedure, AII amacrine cells lost the vast majority of their dendritic arborization when compared with labeled cells in vertical sections or filled cells in a retinal slice preparation (Figs. $2 B$, $3 A$ ). Dissociated parvalbumin-positive cells were characterized by a medium-sized cell body and a stout primary dendrite, usually branching into two thinner dendrites (Fig. 3D,E). However, the few remaining dendrites clearly displayed $\mathrm{Cx} 36$-positive labeling (Fig. $3 D, E$ ). In agreement with the results obtained from vertical 

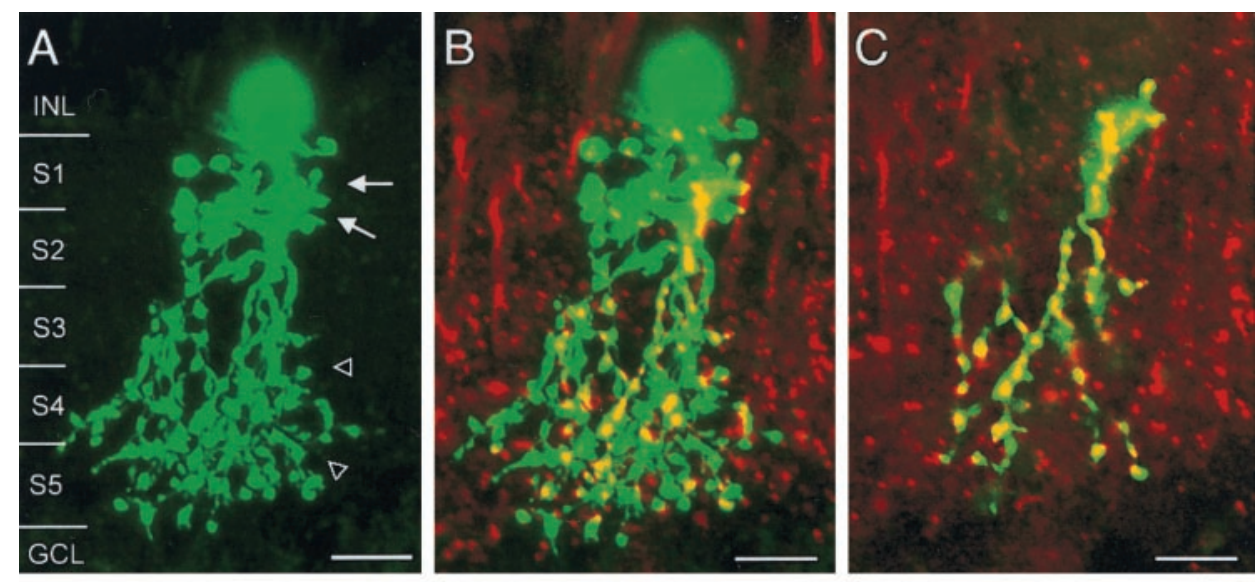

Figure 3. Cx36 immunoreactivity on injected and isolated AII amacrine cells. $A$, AII amacrine of the mouse retina filled with Neurobiotin and visualized with streptavidin-FITC. The picture represents a superimposed stack of 40 confocal images of $200 \mathrm{~nm}$ each. The stratification levels S1-S5 of the IPL are indicated as horizontal lines to the left. The bistratified morphology of this cell type with lobular appendages in S1 (arrows) and a narrow-field dendritic tree in S3-S5 (arrowheads) is apparent. $B$, Pattern of Cx36 immunoreactivity superimposed on the cell shown in $A$. $C$, Single $200 \mathrm{~nm}$ confocal section of the same cell, superimposed on $\mathrm{Cx} 36$ staining pattern in the IPL. The cell body and most of the dendritic arborization are out of focus. $D, E$, Isolated AII amacrine cells from the rat retina doublelabeled with antibodies against parvalbumin (red) and Cx36 (green). The cells display Cx36 immunoreactivity on their distal dendrites. Scale bars: $A-E, 10 \mu \mathrm{m}$.
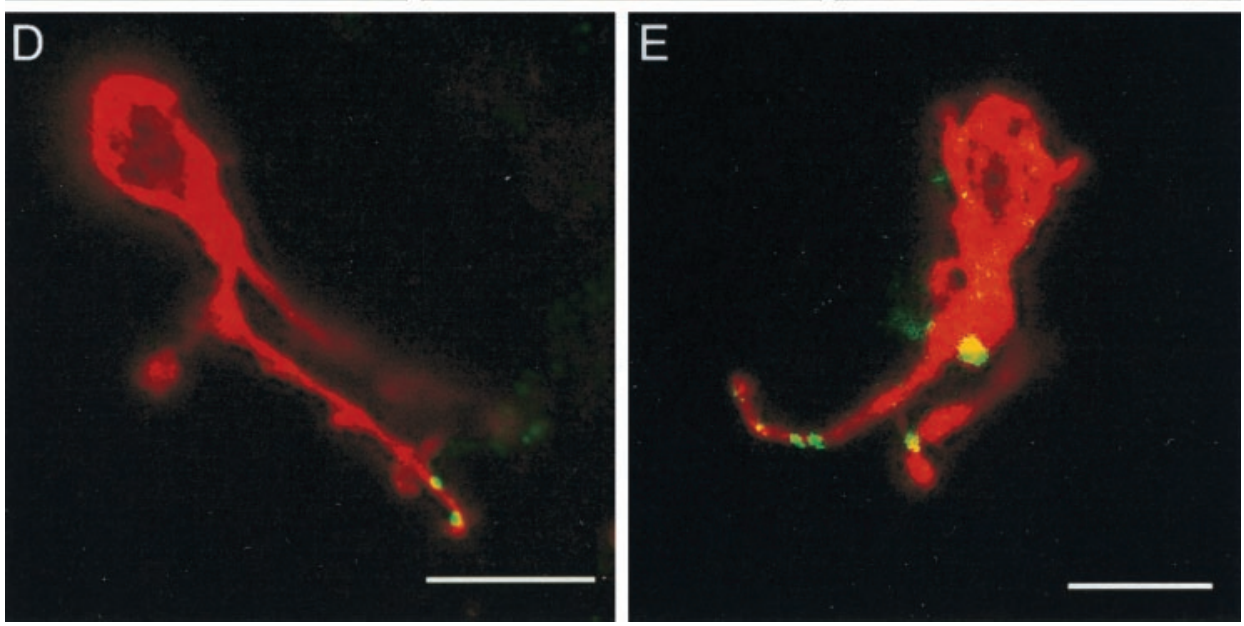

sections, Cx36-positive puncta were expressed in a distance from the cell body appropriate to span the outer half of the IPL. We observed Cx36 labeling on all parvalbumin-positive cells with at least one preserved dendrite $(n=10)$ but never on those parvalbumin-positive cells that had lost their dendritic tree with only the cell body remaining $(n=15)$. In addition, we did not detect Cx36 immunoreactivity on dendrites or cell bodies of parvalbumin-negative cells in this preparation.

The colocalization of $\mathrm{Cx} 36$ on parvalbumin-positive dendrites in the ON sublamina suggests that Cx36 is expressed by AII amacrine cells. Cx36 appears to be differentially distributed within the cells, with colocalization mostly restricted to dendrites located in the ON sublamina, whereas lobular appendages and cell bodies show little or no Cx36 labeling.

\section{Is Cx36 expressed by cone bipolar cells?}

We next addressed the question whether or not heterologous gap junctions between AII amacrine and ON cone bipolar cells are also homotypic with respect to expression of Cx36. Unfortunately, no selective immunocytochemical marker for cone bipolar cells is available for the mouse retina. In this species, recoverin stains photoreceptors and very few bipolar cells but in an arbitrary and inconsistent manner (data not shown). An antibody directed against the $\alpha$ subunit of the G-protein $G_{o}$ which is associated with depolarizing bipolar cells, produced homogeneous labeling in the IPL and thus could not be used to resolve axon terminal structures (data not shown). Therefore, cell bodies located in the upper half of the INL were injected with a combination of LY and Neurobiotin as described above for AII amacrine cells. The cells were chosen at random and very briefly filled with LY to evaluate their overall morphology. Only those cells displaying apparently intact axon terminals in the ON sublamina of the IPL were subsequently filled with Neurobiotin and counterstained with an antibody directed against Cx36. A total number of five $\mathrm{ON}$ bipolar cells were processed this way.

Figure $4 A$ shows an $\mathrm{ON}$ cone bipolar cell visualized with streptavidin-FITC. The oval cell body is located in the scleral aspect of the INL, and few dendrites are visible running toward the OPL. A thin axon emerges from the soma and extends through the IPL before radiating into a terminal structure within the ON sublamina. This picture represents a stack of 34 optical sections, $0.2 \mu \mathrm{m}$ each, plotted into a single plane. In Figure $4 B$, the immunolabeling against $\mathrm{Cx} 36$, corresponding to an optical section of $0.2 \mu \mathrm{m}$, is superimposed on the $\mathrm{ON}$ bipolar cell. Cell body and dendrites, as well as the proximal part of the axon, display no overlap, whereas in the region of the axon terminal, Cx36-positive puncta appear to be localized on or in close vicinity of bipolar cell terminal structures. At higher magnification, Cx36positive puncta apparently cut in cross-section can be observed decorating individual dendrites within the terminal structure (Fig. $4 C$, arrows). In this case, the staining does not overlap. In contrast, circular Cx36-immunoreactive plaques were occasionally observed that appeared to be located on bipolar cell axon terminals (Fig. 4C, arrowheads).

In the rat retina, a polyclonal antibody directed against recoverin identifies a population of ON cone bipolar cells (Milam et al., 1993; Euler and Wässle, 1995). Double-labeling of vertical sections did indicate sparse colocalization, comparable with the results obtained with injected $\mathrm{ON}$ bipolar cells in the mouse 

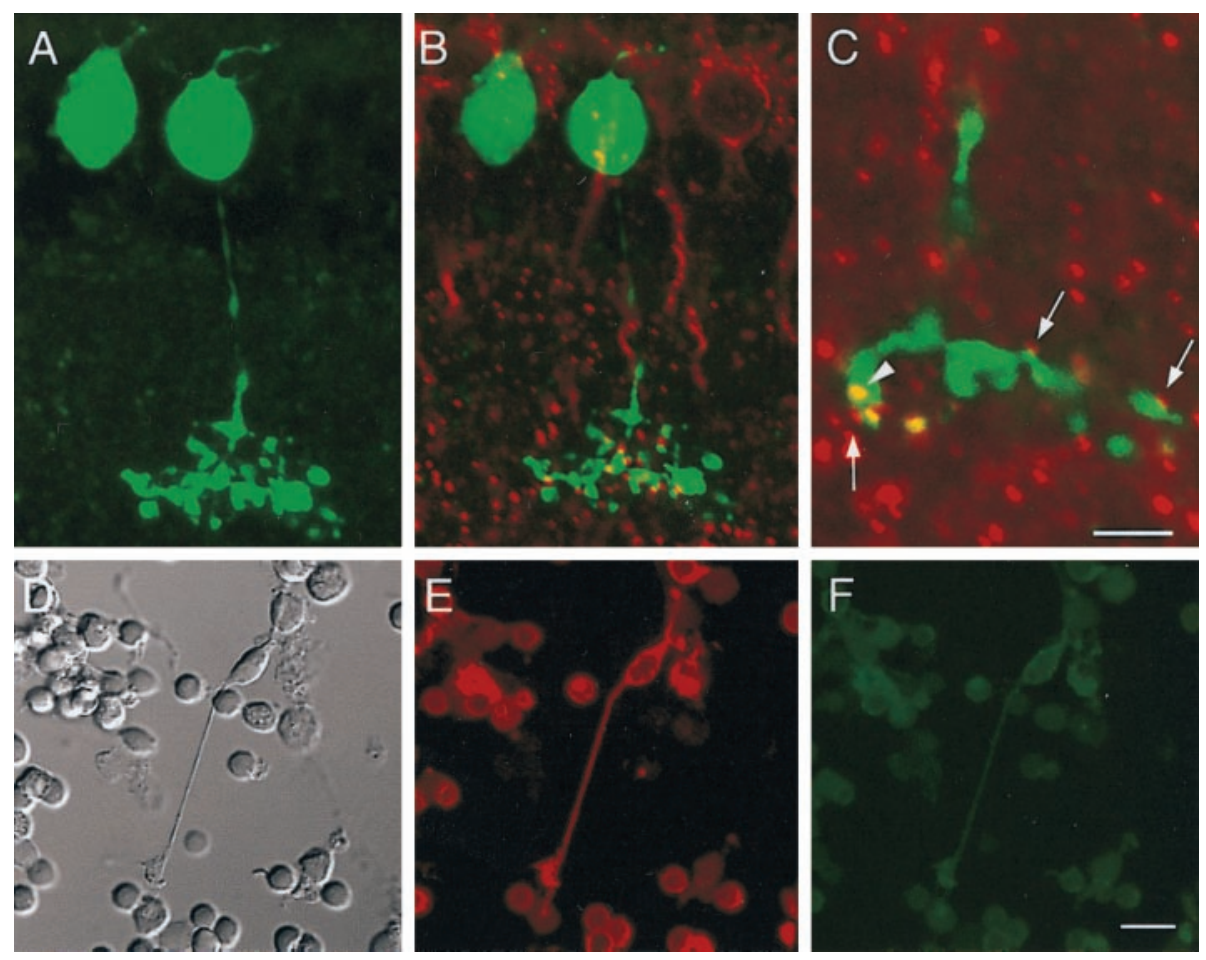

Figure 4. Injected and isolated $\mathrm{ON}$ cone bipolar cells do not display $\mathrm{Cx} 36$ immunoreactivity. $A, \mathrm{ON}$ cone bipolar cell of the mouse retina filled with Neurobiotin and visualized with streptavidinFITC. The picture represents a superimposed stack of 34 confocal images of $200 \mathrm{~nm}$ each. $B$, Pattern of Cx36 immunoreactivity superimposed on the cell shown in $A$. $C$, Enlarged view of the axon terminal system of the same cell. Superimposed are $200 \mathrm{~nm}$ confocal sections of Neurobiotin and Cx36 staining. Cx36-immunoreactive puncta appear as cut vertically (arrows) or horizontally (arrowhead). D, Nomarski image of a cone bipolar cell isolated from the rat retina. $E$, The same cell shows immunoreactivity against recoverin and can therefore be identified as an ON cone bipolar cell. The numerous small, round cell bodies are photoreceptors that are also positive for recoverin. $F$, The same cell is not immunoreactive for Cx36. Scale bars: $A-C, 10$ $\mu \mathrm{m} ; D-F, 10 \mu \mathrm{m}$.

retina (data not shown). To identify $\mathrm{Cx} 36$ on isolated $\mathrm{ON}$ cone bipolar cells, retinas of the rat were dissociated and stained with both recoverin and $\mathrm{Cx} 36$. Figure $4 D$ shows a Nomarski picture of an isolated bipolar cell. The overall shape of the cell appears well preserved, with several dendrites emerging from a cone-shaped cell body and a long axon leaving the soma on the opposite side and finally branching into a partially intact axon terminal system. Immunostaining with recoverin indicates that this cell is a cone bipolar cell, most likely an ON cone bipolar cell given the length of the axon (Fig. 4E). Double-labeling with antibody against Cx36, however, did not reveal a positive signal in the axon terminal (Fig. $4 F$ ), indicating that $\mathrm{Cx} 36$ is not expressed by this cell.

We never observed Cx36 immunoreactivity on isolated bipolar cells, suggesting that the population of recoverin-positive $\mathrm{ON}$ cone bipolar cells does not express Cx36 in their gap junctions with AII amacrines. Recoverin-positive OFF cone bipolar cells, which could be easily identified by their shorter axon, also lacked Cx36-positive puncta.

\section{Cx36 is not expressed by rod bipolar cells}

PKC has been demonstrated to be primarily expressed by rod bipolar cells in the mammalian retina (Negishi et al., 1988; Greferath et al., 1990), and therefore a monoclonal antibody to PKC can be used to identify rod bipolar cells in vertical sections of the mouse and rat retina. Figure $5 A$ shows a vertical section of the rat retina double-labeled with antibodies against $\mathrm{PKC}$ and Cx36. PKC-like immunoreactivity is found in the cell bodies and dendrites of rod bipolar cells, as well as in their axons, which terminate close to the ganglion cell layer. When double-stained with Cx36, rod bipolar axon terminal systems appear to be decorated with Cx36-positive puncta (Fig. $5 A$, inset, arrows). The vast majority of these puncta appear to be attached to the surface of the axon terminals, with no significant overlap in staining, suggesting that rod bipolar cells do not express Cx36 themselves. To test this hypothesis, we dissociated rod bipolar cells from the mouse and rat retina. The isolated cells were identified with antibodies to PKC and checked for Cx36 immunoreactivity. The results obtained from a rat retina are summarized in Figure $5 B-D$. The Nomarski image (Fig. $5 B$ ) shows a typical rod bipolar cell with well preserved morphology that is PKC-positive (Fig. $5 C$ ). However, there is no indication of expression of $\mathrm{Cx} 36$ in the axon terminal structure as suggested by the results of Figure $5 A$. The single Cx36-positive puncta in the middle of the axon is most likely caused by debris still attached, as can be seen in the transmission image. We never observed Cx36 immunoreactivity on all rod bipolar cells tested $(n=25)$. These results strongly suggest that rod bipolar cells of the rodent retina do not express Cx36.

\section{DISCUSSION}

In this study, we used double-labeling immunocytochemistry to elucidate the distribution of $\mathrm{Cx} 36$ in the mouse and rat retina. We confirm the expression of $\mathrm{Cx} 36$ in the inner plexiform layer of the mouse retina and additionally describe a very similar distribution of $\mathrm{Cx} 36$ in the retina of the rat. The pattern of staining displayed a punctate appearance as expected for labeling of gap junctional structures. Colocalization with parvalbumin in the rat retina indicates that $\mathrm{Cx} 36$ is expressed on the dendritic arborization of AII amacrine cells. The same holds true for the mouse retina in which Cx36-positive puncta could be localized on the dendrites of Neurobiotin-filled AII amacrine cells. Isolated AII amacrine cells, identified by their parvalbumin immunoreactivity, also showed punctate Cx36 labeling on their arboreal dendrites, confirming the expression of this connexin by this cell type.

When the IPL was divided into five equally thick strata, named S1-S5 when proceeding from the INL to the GCL, colocalization was restricted from S3 through S5 and thus to sublamina b of the IPL. Punctate labeling mainly in S1 and S2 did not overlap significantly with lobular appendages of AII amacrine cells, in agreement with the reported lack of gap junctions in this region 
Figure 5. Rod bipolar cells do not express Cx36. $A$, Double-labeling of a vertical section of rat retina with antibodies against PKC (green) and Cx36 (red). A region of the section with pronounced decoration of rod bipolar terminals with $\mathrm{Cx} 36-$ positive puncta (arrows) is enlarged in the inset. $B$, Nomarski image of an isolated rod bipolar cell. $C$, Corresponding staining against PKC. $D$, The same cell is not immunoreactive for $\mathrm{Cx} 36$. Scale bars: $A$ $25 \mu \mathrm{m}$; inset in $A, 10 \mu \mathrm{m} ; B-D, 10 \mu \mathrm{m}$.
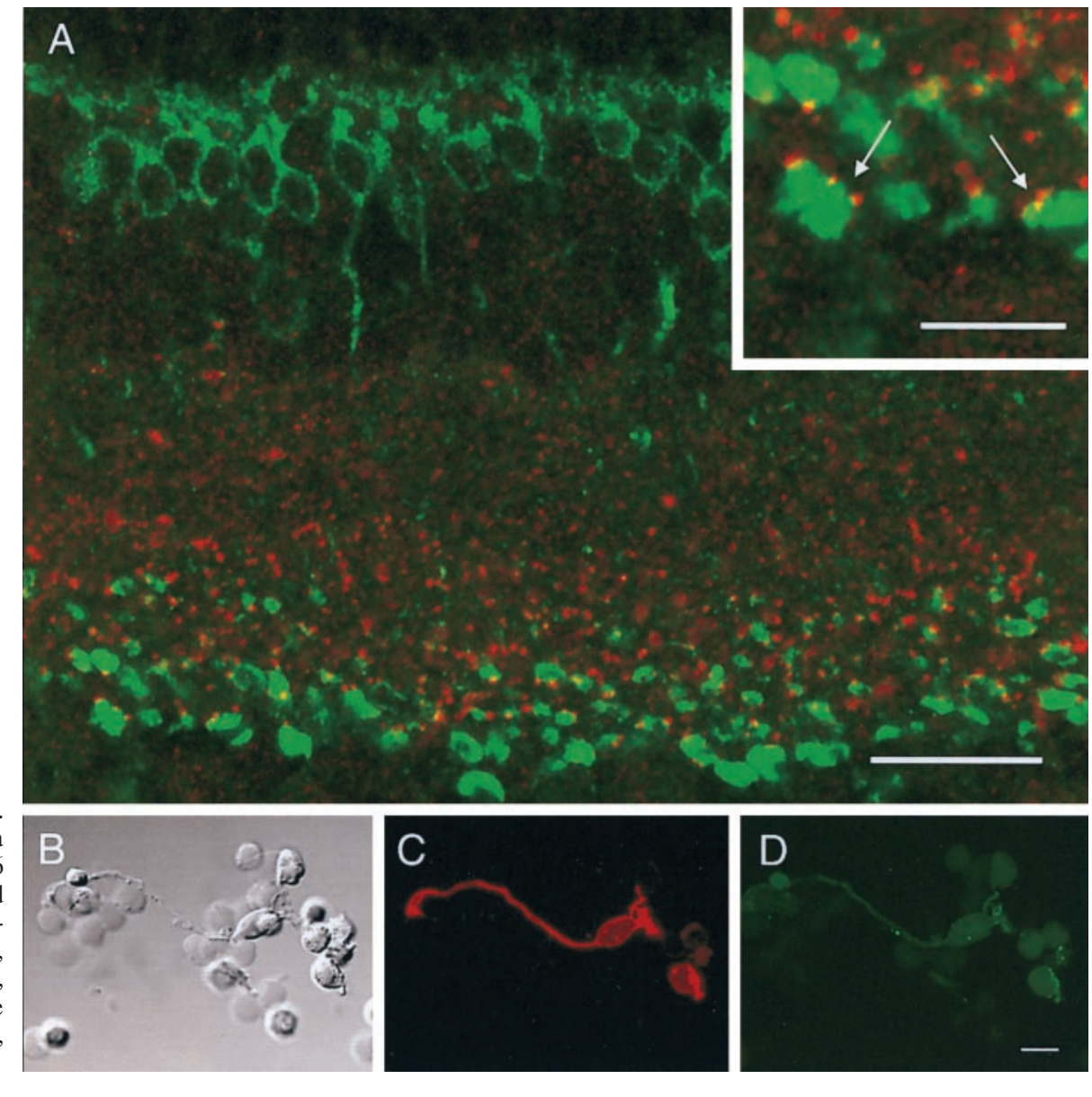

(Strettoi et al., 1992). Cx36 immunoreactivity in the OFF sublamina indicates that a cell type other than AII amacrines expresses $\mathrm{Cx} 36$. It is possible that this staining originates from other amacrine cells, axon terminals of OFF bipolar cells, or ganglion cells with stratification levels in S1 and S2. Interestingly, in preparations of dissociated cells, Cx36 immunoreactivity was never found on parvalbumin-negative cells. This could of course be attributable to the fact that most of the processes of the cells are lost during the dissociation procedure. However, assuming that $\mathrm{Cx} 36$ is expressed in parvalbumin-negative cells, one would expect at least occasional labeling. We are currently trying to identify the cellular origin of Cx36 expression in the outer half of the IPL. Therefore, the presence of $\mathrm{Cx} 36$ on AII amacrine dendrites in S3-S5 most likely indicates its expression in heterologous gap junctions between AII amacrine cells and ON cone bipolar cells. The occurrence of $\mathrm{Cx} 36$ on the most remote AII dendrites in S5 close to the GCL suggests that Cx36 is expressed in homologous gap junctions between pairs of AII amacrine cells, because homologous gap junctions have been localized to S5 in the rabbit retina (Strettoi et al., 1992) (for a schematic drawing of the wiring of AII amacrine cells in the IPL, see Fig. 6). Thus far, no other junctional contacts have been described in this region of the IPL.

Whereas the above results strongly suggested that the homologous AII coupling is homotypic, the situation for the heterologous coupling between AII amacrine cells and cone bipolar cells was more difficult to answer. Injected $\mathrm{ON}$ cone bipolar cells showed partial Cx36 immunoreactivity on their axonal ramifications in the IPL. This signal, however, could have originated from the adjacent AII dendrite despite an optical slice thickness of 0.2 $\mu \mathrm{m}$. To address this point, we used an antibody against recoverin as a marker for a population of ON cone bipolar cells (Milam et al., 1993; Sassoè-Pognetto et al., 1994; Euler and Wässle, 1995). In the rabbit retina, a recoverin-positive cone bipolar cell has been shown to be well coupled to AII amacrine cells, accounting for $\sim 23 \%$ of cone bipolar cells coupled to AII amacrine cells (Massey and Mills, 1996). Interestingly, the same cell type shares many morphological characteristics with a reconstructed cone bipolar cell, which forms most gap junctions with AII amacrine cells (Strettoi et al., 1994). We never found colocalization on axon terminals of recoverin-positive ON cone bipolar cells. The few spots that we sometimes observed resulted from cell debris overlaying the bipolar cells as revealed with Nomarski optics. We therefore can exclude that recoverin-positive cone bipolar cells contain Cx36 in their gap junctions with AII amacrine cells. Anti-recoverin labeling identifies only a fraction of cone bipolar cells in the rat retina. In a dissociated retina preparation, bipolar cells lose most of their dendrites, but their overall morphology is rather well preserved. If $\mathrm{Cx} 36$ is not expressed on the most remote dendrites of these cells, we would at least expect some labeling, but we never detected Cx36 immunoreactivity in morphologically identified bipolar cells isolated from the mouse and rat retina.

We cannot exclude the possibility that papain effects the level of Cx36 expression in isolated retinal neurons. Electrophysiological studies performed in the same preparation, however, do not indicate altered properties of membrane-bound proteins such as transmitter receptors or voltage-gated ion channels (Gustincich et 


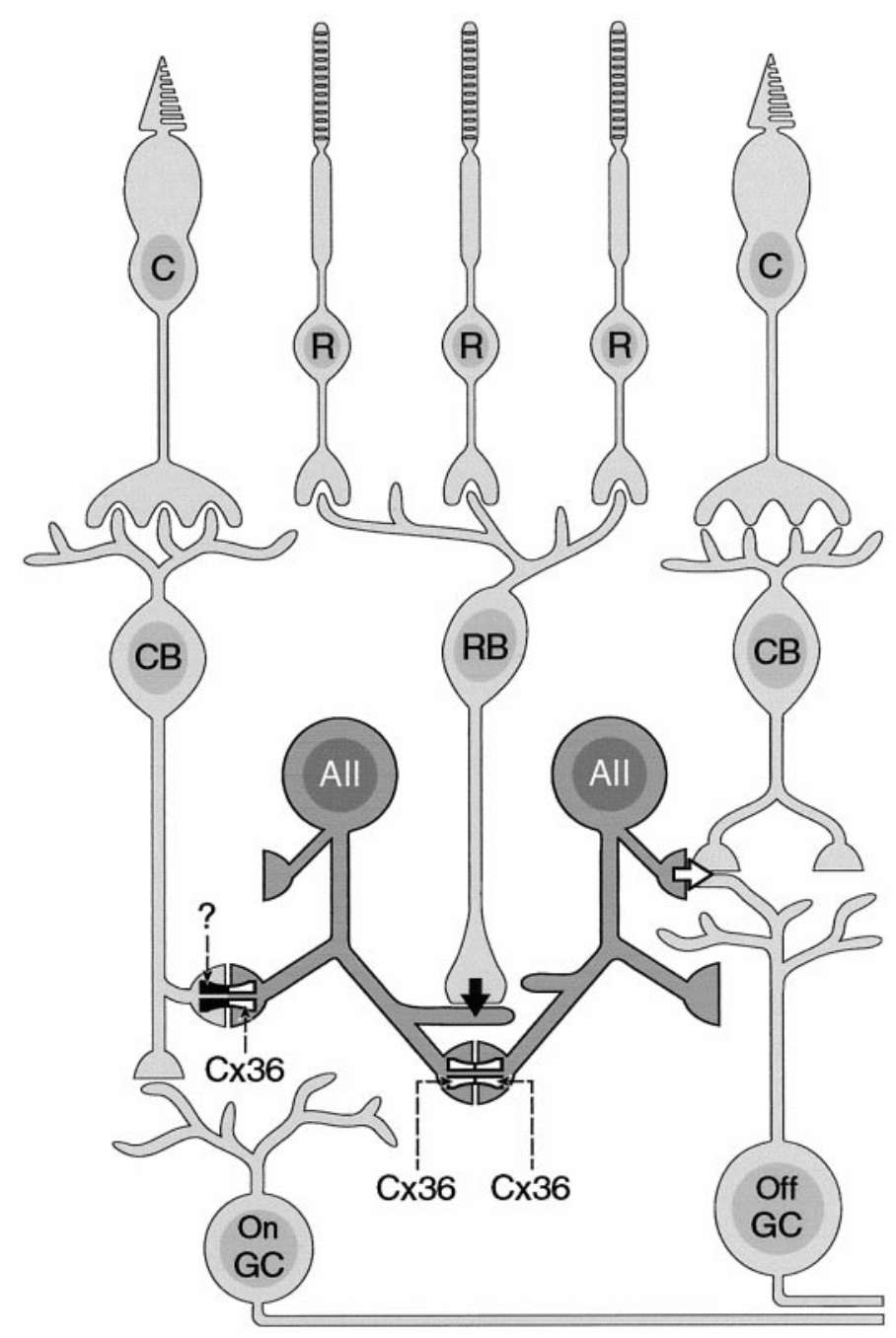

Figure 6. Schematic drawing indicating the wiring of the mammalian retina in the IPL. AII amacrine cells make homotypic gap junctions containing $\mathrm{Cx} 36$ with other AII amacrines in the innermost layer of the IPL (depicted as $C x 36-C x 36$ ). In addition, heterotypic gap junctions with Cx36 expressed by AII amacrine cells $(C x 36-?)$ are made with cone bipolar cells. $C$, Cones; $R$, rods; $C B$, cone bipolar cells; $R B$, rod bipolar cells; $A I I$, AII amacrine cells; $G C$, ganglion cells.

al., 1997). In addition, the antibody to Cx36 is directed against an intracellular epitope, and therefore immunocytochemical detection should not be directly influenced by the dissociation procedure.

In a recent study, Al-Ubaidi et al. (2000) use an antibody raised against the intracellular loop of perch $\mathrm{Cx} 35$ to localize Cx36 in the mouse retina. In contrast to our study, their antibody recognized cellular structures in the inner nuclear and ganglion cell layer. A likely explanation for these apparent discrepancies is the fact that the intracellular loops of perch Cx35 and mouse Cx36 share only $67 \%$ identity. The cellular staining pattern as described by Al-Ubaidi et al. is not typical for labeling of gap junctions; rather, a punctate pattern would be expected. The antibody used in the present study, however, was raised against the intracellular loop of mouse $\mathrm{Cx} 36$, and therefore it is likely that both antibodies detect different epitopes.

In two electron microscopic studies performed in the cat and rabbit retina, it has been shown that amacrine to bipolar gap junctions display a structural asymmetry with the cytoplasmic aspect of the AII cell membrane being characterized by a layer of "fluffy material" (Kolb 1979; Strettoi et al., 1992). In contrast, homologous gap junctions formed by AII amacrine cells lack the fluffy material. If this material is a structural correlate to connexin diversity, this also would indicate expression of different connexins on the AII side in heterologous versus homologous gap junctions. Immunocytochemistry with antibodies against $\mathrm{Cx} 26$, $\mathrm{Cx} 37, \mathrm{Cx} 43$, and $\mathrm{Cx} 45$ did reveal the presence of these connexins in the mouse retina, but none of these was expressed in the ON sublamina of the IPL (Güldenagel et al., 2000).

Functional properties of connexin36 have been studied in communication-deficient cell lines stably transfected with $\mathrm{Cx} 36$ (Srinivas et al., 1999; Teubner et al., 2000). In agreement with the staining pattern observed in vertical sections of the mouse and rat retina described here, immunocytochemical analysis of transfected HeLa cells yielded punctate labeling of connexin expression of cultured cells on contacting membranes (Teubner et al., 2000). The authors of this study also demonstrated that coupled HeLa cells display tracer coupling when injected with Neurobiotin but do not show transfer of the dye Lucifer yellow. However, Srinivas et al. (1999) report that Cx36 channels expressed in neuroblastoma and PC-12 cells are permeable to Lucifer yellow. Therefore, the functional properties of gap junctions containing Cx36 might differ according to the cellular environment in which they are expressed. In addition, a series of heterotypically coupled cell pairs with Cx36 and Cx26, Cx30, Cx31, Cx32, Cx37, Cx40, $\mathrm{Cx} 43$, Cx45, or Cx50 was tested (Teubner et al., 2000). In none of these cocultures transfer of either Neurobiotin or Lucifer yellow could be observed. Also, the homolog from the skate retina, Cx35, did not form heterotypic channels when coexpressed in Xenopus oocytes with Cx26, Cx32, Cx46, and Cx50 (White et al., 1999).

These data suggest that members of the $\gamma$ family form functional channels only in homotypic configurations and not with members of the two other families. Therefore, the yet unknown partner of $\mathrm{Cx} 36$ in the heterologous AII-cone bipolar coupling should either be an as yet unidentified member of the $\gamma$ family or a splice variant of $\mathrm{Cx} 36$ that is not recognized by the antibody. The existence of splice variants of Cx36 is very likely because, in this connexin, the coding region is interrupted by an intron (Teubner et al., 2000). The splice junction lies close to the presumptive transition from the $\mathrm{N}$ terminus to the first transmembrane domain, which is responsible for the voltage sensitivity. The alternative splicing could therefore lead to expression of different forms of Cx36 with altered gating properties. This would also explain that, under light-adapted conditions, AII amacrine cells only show a very small cone-driven response, quite in contrast to the strong sustained responses obtained from cone bipolar cells (Nelson, 1982; Dacheux and Raviola, 1986). This could indicate that heterologous gap junctions are asymmetric in terms of signal rectification toward the amacrine cell. As pointed out by Vaney (1997), there have been no reports that cone bipolar cells injected with Neurobiotin show tracer coupling to AII amacrine cells, in contrast to the extensive network observed when tracer is injected into the AII amacrine cell (Vaney 1991, 1994; Vaney et al., 1991; Hampson et al., 1992).

Homologous and heterologous gap junctions appear to be differentially regulated; whereas dopamine and cAMP exert a powerful effect on the uncoupling of gap junctions between AII amacrine cell pairs, it has no effect on heterologous gap junctions (Hampson et al., 1992; Mills and Massey, 1995). Instead, ama- 
crine to bipolar gap junctions are uncoupled by nitric oxide and cGMP agonists, as indicated by the reduction of tracer coupling between these cell types (Mills and Massey, 1995). The differences in the pharmacological regulation of heterologous and homologous gap junctions could reflect differences in the connexin composition of the hemichannels. These differences in turn could arise from expression of two different connexins or from the post-translational modification of a single type of connexin. Analysis of the amino acid sequence of $\mathrm{Cx} 36$ reveals consensus sites for the binding of both cAMP-dependent and cGMPdependent protein kinase, accumulating in the C-terminal domain (Söhl et al., 1998).

A striking observation was the intimate association of punctate Cx36 immunoreactivity with the axonal arborizations of rod bipolar cells. We could exclude that rod bipolar cells express Cx36 by themselves. The frequent and robust labeling must therefore result from profiles of unknown origin, which are in very close contact with the axonal terminals of rod bipolar cells and express Cx36 at these sites. So far there is no report about any gap junctional contact made by rod bipolar cell terminals. It therefore remains to be elucidated whether the observed $\mathrm{Cx} 36$ labeling represents a gap junctional contact or reflects the presence of hemichannels.

\section{REFERENCES}

Al-Ubaidi MR, White TW, Ripps H, Poras I, Avner P, Gomès D, Bruzzone R (2000) Functional properties, developmental regulation, and chromosomal localization of murine connexin36, a gap-junctional protein expressed preferentially in retina and brain. J Neurosci Res 59:813-826.

Beyer EC, Paul DL, Goodenough DA (1990) Connexin family of gap junction proteins. J Membr Biol 116:187-194.

Bruzzone R, White TW, Goodenough DA (1996) The cellular internet: on-line with connexins. BioEssays 18:709-718.

Chun MH, Han SH, Chung JW, Wässle H (1993) Electron microscopic analysis of the rod pathway of the rat retina. J Comp Neurol 332:421-432.

Condorelli DF, Parenti R, Spinella F, Trovato Salinaro A, Belluardo N, Cardile V, Cicirata F (1998) Cloning of a new gap junction gene (Cx36) highly expressed in mammalian brain neurons. Eur J Neurosci 10:1202-1208.

Cook JE, Becker DL (1995) Gap junctions in the vertebrate retina. Microsc Res Tech 31:408-419.

Dacheux RF, Raviola E (1986) The rod pathway in the rabbit retina: a depolarizing bipolar and amacrine cell. J Neurosci 6:331-345.

Dahl E, Manthey D, Chen Y, Schwarz HJ, Chang YS, Lalley PA, Nicholson BJ, Willecke K (1996) Molecular cloning and functional expression of mouse connexin-30, a gap junction gene highly expressed in adult brain and skin. J Biol Chem 271:17903-17910.

Dermietzel R, Spray DC (1998) From glue ("nervenkitt") to glia: a prologue. Glia 4:1-7.

Draguhn A, Traub RD, Schmitz D, Jeffreys JG (1999) Electrical coupling underlies high frequency oscillations in the hippocampus in vitro. Nature 394:189-192.

Euler T, Wässle H (1995) Immunocytochemical identification of cone bipolar cells in the rat retina. J Comp Neurol 361:461-478.

Famiglietti EV, Kolb H (1975) A bistratified amacrine cell and synaptic circuitry in the inner plexiform layer of the retina. Brain Res 84:293-300.

Galarreta W, Hestrin S (1999) A network of fast-spiking cells in the neocortex connected by electrical synapses. Nature 402:72-75.

Goodenough DA, Goliger JA, Paul DL (1996) Connexins, connexons, and intercellular communication. Annu Rev Biochem 65:475-502.

Greferath U, Grünert U, Wässle H (1990) Rod bipolar cells in the mammalian retina show protein kinase C-like immunoreactivity. J Comp Neurol 301:433-442.

Güldenagel M, Söhl G, Traub O, Teubner B, Weiler R, Willecke K (2000) Expression patterns of connexin genes in mouse retina. J Comp Neurol 425:193-201.

Gustincich S, Feigenspan A, Wu DK, Koopman LJ, Raviola E (1997) Control of dopamine release in the retina: a transgenic approach to neural networks. Neuron 18:723-736.

Haefliger JA, Bruzzone R, Jenkins NA, Gilbert DJ, Copeland NG, Paul DL (1992) Four novel members of the connexin family of gap junction proteins. Molecular cloning, expression, and chromosome mapping. J Biol Chem 267:2057-2064.
Hampson ECGM, Vaney DI, Weiler R (1992) Dopaminergic modulation of gap junction permeability between amacrine cells in mammalian retina. J Neurosci 12:4911-4922.

Janssen-Bienhold U, Dermietzel R, Weiler R (1998) Distribution of connexin 43 immunoreactivity in the retinas of different vertebrates. J Comp Neurol 396:310-321.

Kolb H (1979) The inner plexiform layer in the retina of the cat: electron microscopic observations. J Neurocytol 8:295-329.

Kolb H, Famiglietti EV (1974) Rod and cone pathways in the inner plexiform layer of the cat retina. Science 186:47-49.

MacNeil M, Heussy JK, Dacheux RF, Raviola E, Masland RH (1999) The shapes and numbers of amacrine cells: matching of photofilled with Golgi-stained cells in the rabbit retina and comparison with other mammalian species. J Comp Neurol 413:305-326.

Massey SC, Mills SL (1996) A calbindin-immunoreactive cone bipolar cell type in the rabbit retina. J Comp Neurol 366:15-33.

Milam AH, Dacey DM, Dizhoor AM (1993) Recoverin immunoreactivity in mammalian cone bipolar cells. Vis Neurosci 10:1-13.

Mills SL, Massey SC (1995) Differential properties of two gap junctional pathways made by AII amacrine cells. Nature 377:734-737.

Negishi K, Kato S, Teranishi T (1988) Dopamine cells and rod bipolar cells contain protein kinase C-like immunoreactivity in some vertebrate retinas. Neurosci Lett 94:247-252.

Nelson R (1982) AII amacrine cells quicken time course of rod signals in the cat retina. J Neurophysiol 47:928-947.

O'Brien J, Al-Ubaidi MR, Ripps H (1996) Connexin35: a gap-junctional protein expressed preferentially in the skate retina. Mol Biol Cell 7:233-243.

O’Brien J, Bruzzone R, White TW, Al-Ubaidi MR, Ripps H (1998) Cloning and expression of two related connexins from the perch retina define a distinct subgroup of the connexin family. J Neurosci 18:7625-7637.

Perry VH, Walker M (1980) Amacrine cells, displaced amacrine cells and interplexiform cells in the retina of the rat. Proc R Soc Lond B Biol Sci 208:415-431.

Sassoè-Pognetto M, Wässle H, Grünert U (1994) Glycinergic synapses in the rod pathway of the rat retina: cone bipolar cells express the alpha 1 subunit of the glycine receptor. J Neurosci 14:5131-5146.

Söhl G, Degen J, Teubner B, Willecke K (1998) The murine gap junction gene connexin36 is highly expressed in mouse retina and regulated during brain development. FEBS Lett 428:27-31.

Srinivas M, Rozental R, Kojima T, Dermietzel R, Mehler M, Condorelli DF, Kessler JA, Spray DC (1999) Functional properties of channels formed by the neuronal gap junction protein connexin36. J Neurosci 19:9848-9855.

Sterling P (1995) Tuning retinal circuits. Nature 377:676-677.

Strettoi E, Masland RH (1996) The number of unidentified amacrine cells in the mammalian retina. Proc Natl Acad Sci USA 93:14906-14911.

Strettoi E, Dacheux RF, Raviola E (1992) Synaptic connections of the narrow-field, bistratified rod amacrine cell (AII) in the rabbit retina. J Comp Neurol 325:152-168.

Strettoi E, Dacheux RF, Raviola E (1994) Cone bipolar cells as interneurons in the rod pathway of the rabbit retina. J Comp Neurol $347: 139-149$

Tamas G, Buhl EH, Lorincz A, Somogyi P (2000) Proximally targeted GABAergic synapses and gap junctions synchronize cortical interneurons. Nat Neurosci 3:366-371.

Teubner B, Degen J, Söhl G, Güldenagel M, Bukauskas FF, Trexler B, Verselis VK, De Zeeuw CI, Lee CG, Kozak CA, Dermietzel R, Willecke K (2000) Functional expression of the murine connexin 36 gene. J Membr Biol 176:249-262.

Vaney DI (1991) Many diverse types of retinal neurons show tracer coupling when injected with biocytin or Neurobiotin. Neurosci Lett 125:187-190.

Vaney DI (1994) Patterns of neuronal coupling in the retina. Prog Retin Eye Res 13:302-355.

Vaney DI (1996) Cell coupling in the retina. In: Gap junctions in the nervous system (Spray DC, Dermietzel R, eds), pp 79-102. Austin, TX: Landes.

Vaney DI (1997) Neuronal coupling in rod signal pathways of the retina. Invest Ophthalmol Vis Sci 38:267-273.

Vaney DI (1999) Neuronal coupling in the central nervous system: lessons from the retina. In: Gap junction mediated intercellular signalling in health and disease, pp 113-133. Chichester, UK: Wiley.

Vaney DI, Gynther IC, Young HM (1991) Rod-signal interneurons in the rabbit retina. II. AII amacrine cells. J Comp Neurol 310:154-169.

Voigt T, Wässle H (1987) Dopaminergic innervation of AII amacrine cells in mammalian retina. $\mathrm{J}$ Neurosci 7:4115-4128.

Wässle H, Grünert U, Röhrenbeck J (1993) Immunocytochemical staining of AII-amacrine cells in the rat retina with antibodies against parvalbumin. J Comp Neurol 332:407-420.

Weiler R (1996) The modulation of gap junction permeability in the 
retina. In: Gap junctions in the nervous system (Spray DC, Dermietzel R, eds), pp 103-122. Austin, TX: Landes.

Weiler R, Feigenspan A, Teubner B, Willecke K (2000a) Cellular localization of the murine connexin $\mathrm{Cx} 36$ in the mammalian retina. ARVO Abstr: B387.

Weiler R, Pottek M, He S, Vaney DI (2000b) Modulation of coupling between retinal horizontal cells by retinoic acid and endogenous dopamine. Brain Res Rev 32:121-129.

White TW, Bruzzone R, Goodenough DA, Paul DL (1992) Mouse
Cx50, a functional member of the connexin family of gap junction proteins, is the lens fiber protein MP70. Mol Biol Cell 3:711-720.

White TW, Deans MR, O'Brien J, Al-Ubaidi MR, Goodenough DA, Ripps H, Bruzzone R (1999) Functional characteristics of skate connexin35, a member of the $\gamma$ subfamily of connexins expressed in the vertebrate retina. Eur J Neurosci 11:1883-1890.

Willecke K, Hennemann D, Dahl E, Jungblut S, Heynkes R (1991) The diversity of connexin genes encoding gap junctional proteins. Eur J Cell Biol 56:1-7. 